\title{
Epicardial adipose tissue volume is associated with non-alcoholic fatty liver disease and cardiovascular risk factors in the general population
}

This article was published in the following Dove Press journal:

Therapeutics and Clinical Risk Management

\begin{abstract}
Xiangbin Meng, '* Wenyao Wang, ${ }^{2, *}$ Kuo Zhang, ${ }^{2, *}$ Yu Qi, ${ }^{2}$ Shimin An, ${ }^{2}$ Siyuan Wang, ${ }^{2}$ Jilin Zheng, ${ }^{2}$ Joyce Kong, ${ }^{3}$ Henghui Liu, ${ }^{4}$ Jing Wu, ${ }^{4}$ Yong Zhou, ${ }^{5}$ Chuanyu Gao,' Yi-Da Tang²

'Department of Cardiology, Zhengzhou University People's Hospital, Zhengzhou, Henan, China; ${ }^{2}$ Department of Cardiology Medicine, Coronary Heart Disease Center, State Key Laboratory of Cardiovascular Disease, Fuwai Hospital, National Center for Cardiovascular Diseases, Chinese Academy of Medical Sciences and Peking Union Medical College, Beijing, China; ${ }^{3} \mathrm{New}$ York Institute of Technology-College of Osteopathic Medicine, Old Westbury, NY, USA; 'Beijing Recdata Technology Co., Ltd., Beijing, China; ${ }^{5}$ Department of Cardiology, Beijing An Zhen Hospital, Capital Medical University, Beijing Institute of Heart, Lung and Blood Vascular Diseases, Beijing, China

*These authors contributed equally to this work
\end{abstract}

Correspondence: Yi-Da Tang

Department of Cardiology, State Key

Laboratory of Cardiovascular Disease, Fuwai

Hospital, National Center for Cardiovascular

Diseases, Chinese Academy of Medical Sciences and Peking Union Medical College, 167 Beilishi Road, Beijing 100037, China

Tel +86 1088396173

Fax +86 I08839 6171

Email tangyida@fuwaihospital.org

Chuanyu Gao

Department of Cardiology, Zhengzhou

University People's Hospital, 7 Weiwu Road,

Zhengzhou, Henan 450003, China

Email gaocy6802@I63.com
Background: Epicardial adipose tissue (EAT) is considered an important source of bioactive molecules that can influence coronary arteries directly and is related to the concurrent presence of both obstructive coronary stenosis and myocardial ischemia independently. Non-alcoholic fatty liver disease (NAFLD) has become an emergent health problem worldwide.

Aim: This cross-sectional study aimed to address the relationship between the volume of EAT and NAFLD and other cardiovascular risk factors in the general population.

Materials and methods: In this study, we selected a total of 2,238 participants aged at least 40 years from the Jidong community in Tangshan, China. The 64-slice CT was used to survey the volume of EAT and liver ultrasonography was used for the diagnosis of NAFLD. The study cohorts were compared according to EAT volume.

Results: Cardiovascular risk factors, such as coronary artery calcium score, carotid intima-media thickness, NAFLD, and ideal cardiovascular health metrics were also found to be related to EAT. In multivariate logistic regression analysis, NAFLD groups showed significant association with higher EAT volume, after correcting for main cardiovascular disease risk factors (OR [95\% CI], 1.407 [1.117, 1.773]).

Conclusion: Our findings in a general community population provide evidence that EAT is strongly associated with NAFLD and other cardiovascular risk factors.

Keywords: epicardial adipose tissue, EAT, coronary artery calcium, CAC, carotid intima-media thickness, CIMT, ideal cardiovascular health metrics, CVH

\section{Introduction}

Epicardial adipose tissue (EAT) and intra-abdominal fat are both derived from brown adipose tissue during embryonic stage. ${ }^{1}$ As a special form of visceral adipose tissue deposited around the heart, EAT can be found in considerable quantities around subepicardial coronary arteries. ${ }^{2}$ EAT forms a layer between the pericardium and the myocardium, surrounding the heart with no fascial layer separating this adipose tissue from the coronary artery wall and the surface of myocardium. ${ }^{3}$ Epicardial fat and myocardium share a same unobstructed microcirculation, suggesting potential interaction among these tissues. Under physiological conditions, epicardial fat has metabolic, thermogenic (as brown fat), and mechanical (cardio-protective) characteristics. ${ }^{4}$ Studies in cadavers showed that coronary atherosclerotic plaque tends to be more noticeable on the arterial side in contact with EAT deposits; the dissected epicardial fat weight is positively correlated to that of the myocardium. ${ }^{5,6}$ Moreover, EAT is considered a rich source of bioactive molecules that can influence coronary arteries directly, ${ }^{7}$ and is related to the concurrent presence of both obstructive coronary stenosis and myocardial ischemia. ${ }^{8}$ 
Non-alcoholic fatty liver disease (NAFLD) has become a worldwide health concern. Approximately $20 \%-30 \%$ of the general population are affected by NAFLD. ${ }^{9}$ NAFLD patients are at a higher risk of developing cardiovascular changes earlier in life. ${ }^{10} \mathrm{~A}$ previous study suggest that NAFLD is an independent cardiovascular disease (CVD) risk factor. ${ }^{11}$ Several studies have also indicated that CVD is the main cause of death in NAFLD patients. ${ }^{12,13}$ However, the association of NAFLD with CVD may be indirect and due to generalized obesity or ectopic fat, especially EAT. Whether NAFLD could affect visceral adipose tissue outside of the liver has not been studied extensively.

In this study, we aimed to test the relationship between the volume of EAT and NAFLD and cardiovascular risk factors using the diagnosis results of 2,238 people from a northern Chinese community. We confirmed that EAT contributes to the pathogenesis of CVD and is associated with cardiovascular risk factors.

\section{Materials and methods Ethics statement}

This study was performed in accordance with the ethical guidelines of China's regulations and guidelines on good clinical practice and the declaration of Helsinki; the Ethics Committee of the Jidong Oilfield Hospital approved it. All participants provided written informed consent before the start of the study. "Jidong study" is hosted by Capital Medical University. Beijing Recdata Technology Co., Ltd. is responsible for the field management and operation of the project, which is implemented by Jidong Oilfield Hospital. The aim of this project is to establish the first long-term follow-up sub-health cohort in China to observe and explore the occurrence and development of systemic disease in a community population. Beijing Recdata Technology Co., Ltd is responsible for the collection and analysis of clinical data, and the preservation of biological samples. Our research has obtained permission from Capital Medical University, Beijing Recdata Technology Co., Ltd., and Jidong Oilfield Hospital.

\section{Study population}

Participants were recruited from the Jidong community in Tangshan, Hebei, China which mainly consisted of employees of Jidong Co. Ltd. Participants who were willing to provide informed consent were included in the study. From July 2013 to August 2014, 9,078 residents aged 20 years or older were invited to participate in this study at the time of their annual physical examination. Among 9,078 participants, 2,928 subjects who were aged 40 years and above, with complete diagnostic history of coronary CT, carotid artery ultrasound, medical history, and abdominal ultrasound were selected. Two hundred and fifty-eight individuals with a history of CVD (including heart failure, myocardial infarction, atrial fibrillation or any other heart disease), cancer, and stroke; 333 subjects with excessive alcohol consumption ( $10 \mathrm{~g} /$ day for women and $\geq 20 \mathrm{~g} /$ day for men for more than a year); and 99 with positive HbsAg were excluded. A total of 2,238 participants were finally included in the analysis (Figure 1).

A reliable questionnaire expressly designed for this study was used to collect clinical data from all participants. Demographic information (eg, age, gender, household income, level of education, marital status, smoking status, physical activity, and history of diseases) of all participants was collected. A patient was considered diagnosed with hyperlipidemia based on a history of cholesterol, cholesterol lowering medication, a total cholesterol (TC) level $>220 \mathrm{mg} / \mathrm{dL}$, triglycerides $>150 \mathrm{mg} / \mathrm{dL}$, or low-density lipoprotein (LDL) $>160 \mathrm{mg} / \mathrm{dL}$. Those with a self-reported history, current treatment with insulin, oral hypoglycemic agents or fasting blood glucose (FBG) level $>126 \mathrm{mg} / \mathrm{dL}$ were categorized as having diabetes mellitus (DM). ${ }^{24}$

Hypertension diagnosis was given in the presence of at least one of the following: 1) SBP $>140 \mathrm{mmHg}$ or

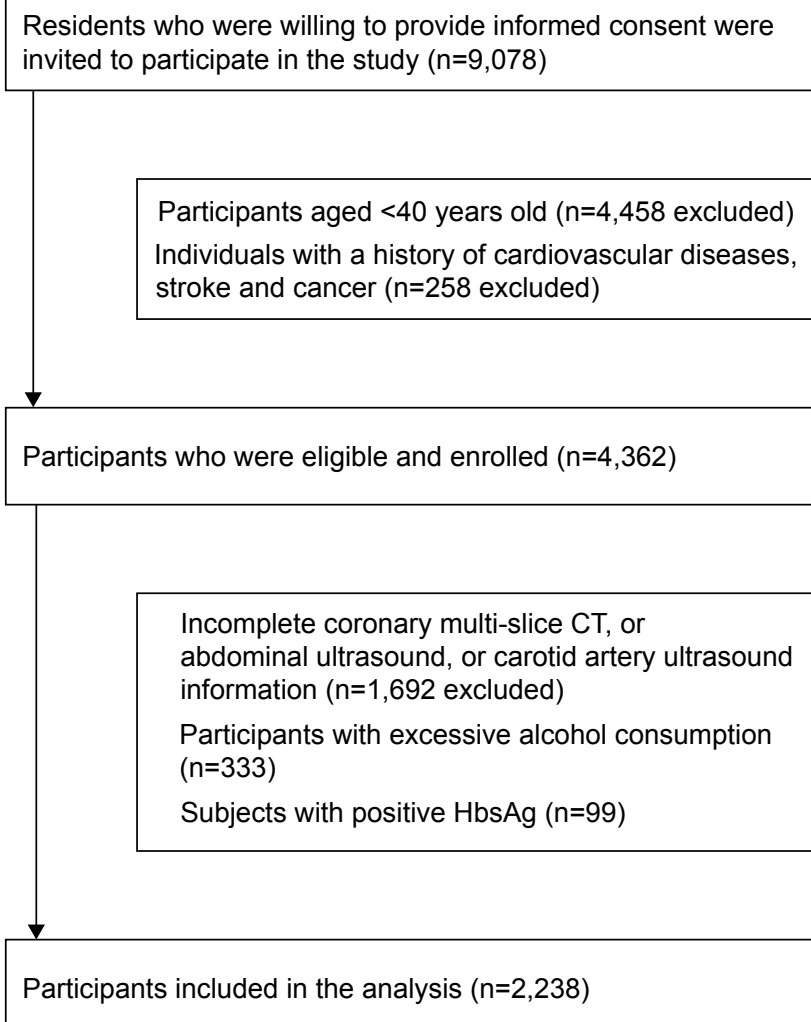

Figure I Flow chart of the enrolled participants who met the requirements. 
DBP $>90 \mathrm{mmHg}, 2$ ) history of antihypertensive medication, or 3 ) history of arterial hypertension. Individuals were classified as being normal weight (18.5-24.9 kg/m²), overweight $\left(25-29.9 \mathrm{~kg} / \mathrm{m}^{2}\right)$ or obese $\left(\geq 30 \mathrm{~kg} / \mathrm{m}^{2}\right) .{ }^{14}$

Automated analyzers (AU400; Olympus Corporation, Tokyo, Japan) were used to analyze samples in the central laboratory of Jidong Oilfield Hospital. Many biological indicators were included such as TC, FBG, serum triglycerides (TG), serum high-density lipoprotein (HDL) cholesterol, LDL cholesterol, AST, Cr, and ALT.

\section{CT imaging and analysis of EAT volume, coronary artery calcium (CAC) score}

$\mathrm{CAC}$ score was defined as at least four contiguous pixels with a CT density of $>130 \mathrm{HU}$ (the Agatston method was used). Total Agatston CAC score was calculated as the sum of all coronary arteries, which was separately calculated according to the Agatston method. ${ }^{25}$

EAT volume was assessed using the same method. EAT was defined as all adipose tissue enclosed by the visceral pericardium, including all fat directly surrounding the coronary arteries. Contiguous dimensional voxels between the HU limits of -195 to -45 were defined as fat voxels; these limits can be modified by the user if deemed appropriate. ${ }^{26}$

\section{Ultrasonography examinations}

Liver ultrasonography was used to diagnose fatty liver, by a high-resolution B-mode topographic ultrasound system with a 3.5 MHz probe (ACUSON X300; Siemens, Munich, Germany). According to Chinese Association for the Study of Liver Disease and the Asia-Pacific Working Party on NAFLD, diagnosis was based on at least two of three abnormal findings: 1) diffusely increased liver near field ultrasound echo; 2) vascular blurring and the gradual attenuation of far field ultrasound echo; 3) liver echo greater than kidney. ${ }^{27,28}$

A sonographer performed carotid intima-media thickness (CIMT) measurements using the same B-mode topographic ultrasound system with a $3.5 \mathrm{MHz}$ probe (ACUSON X300). The operator measured CIMT on the far wall of the right and left common carotid arteries, $1.5 \mathrm{~cm}$ proximal to the bifurcation. The greater value of the right and left common CIMT was used for analysis, CIMT $\geq 0.8 \mathrm{~mm}$ was defined as abnormal. ${ }^{29,30}$

\section{Cardiovascular health metrics assessment} According to the American Heart Association guidelines, we defined the seven cardiovascular health metrics in two levels: "poor" $=0$ score and "ideal" $=1$ score. ${ }^{31}$ The dietary intake metric was classified as ideal (meet the recommended), or poor (did not meet the recommended). The smoking metric was classified as poor (current smoking), or ideal (never- or quit-smoking for $>12$ months). Physical activity was classified as poor (0-149 $\mathrm{min} /$ week of moderate intensity or $0-74 \mathrm{~min} /$ week of vigorous intensity), or ideal ( $\geq 150 \mathrm{~min} /$ week of moderate intensity or $\geq 75 \mathrm{~min} /$ week of vigorous intensity). BMI was classified as poor $\left(\geq 25 \mathrm{~kg} / \mathrm{m}^{2}\right)$, or ideal $\left(<25 \mathrm{~kg} / \mathrm{m}^{2}\right)$. Blood pressure was classified as poor (SBP of $\geq 120 \mathrm{mmHg}$ or DBP of $\geq 80 \mathrm{mmHg}$ ), or ideal (SBP of $<120 \mathrm{mmHg}$, DBP of $<80 \mathrm{mmHg}$, and untreated). FBG level was classified as poor $(100-125 \mathrm{mg} / \mathrm{dL}$ and treated to goal), or ideal ( $<100 \mathrm{mg} / \mathrm{dL}$ and untreated). TC status was classified as poor ( $\geq 200 \mathrm{mg} / \mathrm{dL}$ or treated to goal), or ideal $(<200 \mathrm{mg} / \mathrm{dL}$ and untreated).

\section{Data analysis}

Statistical analysis was performed with SAS software (version 9.4; SAS Institute Inc., Cary, NC, USA). Continuous variables were presented as mean $\pm \mathrm{SD}$ and compared using ANOVA or Student's $t$-test. Categorical variables were described as percentages and compared using chi-squared test; ordinal variables were compared using nonparametric test. Multiple logistic regression was used to test the association between presence of NAFLD and EAT volume. All statistical tests were 2-sided with significance level $\alpha=0.05$.

\section{Results}

Figure 1 showed the flow chart of the enrolled participants who met the requirements. From July 2013 to August 2014, 9,078 Jidong residents aged 20 years or older were invited to participate in this study at the time of their annual physical examination at the Jidong Oilfield Hospital. Finally, a total of 2,238 participants were included in the analysis.

Figure 2 showed that percentage of NAFLD, CIMT $\geq 0.8$ $\mathrm{mm}$ and $\mathrm{CAC}$ score $>0$ all increased with increasing EAT volume. The prevalence of NAFLD in four categories was $28.26 \%, 51.79 \%, 64.11 \%$, and $74.06 \%$. The prevalence of CIMT $\geq 0.8 \mathrm{~mm}$ was $33.27 \%, 49.82 \%, 51.61 \%$, and $64.22 \%$ in four categories, respectively. The prevalence of CAC score $>0$ in four categories was $0.71 \%, 4.82 \%, 10.18 \%$, and $44.01 \%$.

Table 1 showed the baseline characteristics of the study participants, grouped according to quartiles of EAT volume. The mean age of the study participants was $55.6 \pm 7.8$ years (mean $\pm \mathrm{SD}$ ); $43.88 \%$ (982 patients) was within this range. The median EAT volume (interquartile) was $127.46 \mathrm{~cm}^{3}$ $\left(93.87 \mathrm{~cm}^{3}, 172.72 \mathrm{~cm}^{3}\right)$. The prevalence of NAFLD was 


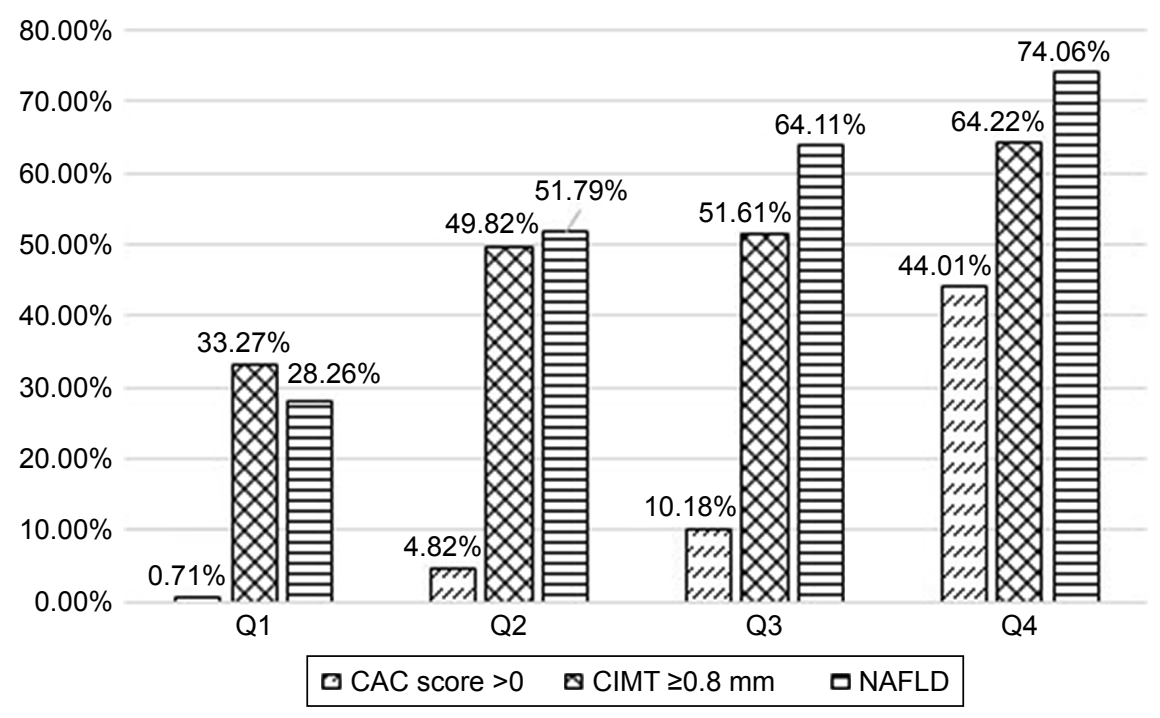

Figure 2 Prevalence of non-alcoholic fatty liver disease, CIMT $\geq 0.8 \mathrm{~mm}$, and CAC score $>0$, by epicardial adipose tissue quartiles. Abbreviations: CIMT, carotid intima-media thickness; CAC, coronary artery calcium; NAFLD, non-alcoholic fatty liver disease.

$28.26 \%, 51.79 \%, 64.11 \%$, and $74.06 \%$ in the four quartiles, respectively $(P<0.001)$. Compared to those with lower volume of EAT, subjects with higher volume of EAT tended to be older, have a larger waist and hip circumference, higher weight, blood pressure, LDL level, FBG level, BMI, triglycerides, and lower HDL level. Furthermore, the percentage of DM, hypertension, and hyperlipidemia increased with increasing EAT volume $(P<0.001)$.

Table 2 showed cardiovascular risk factors of the entire cohort stratified by quartiles of epicardial adipose tissue. Compared to those with lower volume of EAT, subjects with higher volume of EAT tended to have lower ideal cardiovascular health metrics, higher CIMT, and higher CAC scores compared to those with lower prevalence of NAFLD $(P<0.001)$.

Table 3 showed that the OR $(95 \%$ CI) of EAT volume affected the CIMT and CAC score. For all participants, statistically significant correlations/associations were observed, in the crude model as well as three other models adjusted for confounding factors such as traditional risk factors and sociological features (model 1: for CIMT $>0.8 \mathrm{~mm}, 1.033$, [1.023, 1.044], $P<0.0001$; for CAC score $>0,1.230$, [1.204, 1.258], $P<0.0001$; model 2 adjusted for gender and age: for CIMT $>0.8 \mathrm{~mm}, 1.006,[0.998,1.015], P=0.1371$; for CAC score $>0$, 1.213, [1.186, 1.242], $P<0.0001$; model 3: adjusted for level of education and income, smoking status, diabetes, and hypertension on the basis of model 2: for CIMT $>0.8 \mathrm{~mm}, 1.004$, [0.996, 1.013], $P=0.3083$; for CAC score $>0,1.214$, [1.186, 1.243], $P<0.0001$; model 4: adjusted for BMI, on the basis of model 3: for CIMT $>0.8 \mathrm{~mm}, 1.001,[0.993,1.009], P=0.8114$; for CAC score $>0,1.26,[1.225,1.295], P<0.001$ ).

Table 4 showed the multivariate logistic regression analysis of the OR [95\% CI] of groups with NAFLD for higher EAT volume groups (volume $\geq 127.46 \mathrm{~cm}^{3}$ ). For all participants, statistically significant correlations/associations were observed in the crude model as well as three other models adjusted for confounding factors (model 1: 3.346, [2.811, 3.983], $P<0.0001$; model 2 adjusted for gender and age: 3.073, [2.547, 3.708], $P<0.0001$; model 3: adjusted for level of education, smoking status and income, diabetes and hypertension on the basis of model 2: 2.787, [2.787, 2.296], $P<0.0001$; model 4: adjusted for hip circumference, abdominal circumference, TG, LDL, HDL, ALT, BMI, physical activity on the basis of model 3: 1.407, [1.117, 1.773], $P<0.0001)$.

\section{Discussion}

This population-based, cross-sectional study's main finding was that EAT is independently correlated with NAFLD and $\mathrm{CAC}$ score in a community population. Increased EAT volume was strongly correlated with increased NAFLD percentage and many other cardiovascular risk factors, such as CAC score and CIMT and cardiovascular health, in this study. Subjects with higher volume of EAT tended to be older, have a larger waist and hip circumference, higher weight, blood pressure, LDL level, BMI, FBG level, triglycerides, and lower HDL level as well as higher CIMT, lower ideal cardiovascular health metrics, and higher CAC score 
Table I Baseline characteristics of the entire cohort stratified by quartiles of epicardial adipose tissue

\begin{tabular}{|c|c|c|c|c|c|c|}
\hline & \multirow{2}{*}{$\begin{array}{l}\text { Overall } \\
(n=2,238)\end{array}$} & \multicolumn{4}{|c|}{ Quartiles of EAT volume } & \multirow[t]{2}{*}{$P$-value } \\
\hline & & $\begin{array}{l}\text { Ist quartile } \\
(n=559)\end{array}$ & $\begin{array}{l}\text { 2nd quartile } \\
(n=560)\end{array}$ & $\begin{array}{l}\text { 3rd quartile } \\
(n=560)\end{array}$ & $\begin{array}{l}\text { 4th quartile } \\
(n=559)\end{array}$ & \\
\hline Age, years & $55.6 \pm 7.8$ & $51.7 \pm 6.7$ & $55.0 \pm 7.3$ & $56.0 \pm 7.5$ & $59.8 \pm 7.4$ & $<0.000$ I \\
\hline Gender (\%) & & & & & & $<0.000$ I \\
\hline Men & 982 & $137(\mid 3.95)$ & $216(22.00)$ & $282(28.72)$ & $347(35.34)$ & \\
\hline Women & 1,256 & $422(33.60)$ & $344(27.39)$ & $278(22.13)$ & $212(16.88)$ & \\
\hline Education level, (\%) & & & & & & $<0.000$ I \\
\hline Illiterate or primary & 206 & $29(14.08)$ & $48(23.30)$ & $55(26.70)$ & $74(35.92)$ & \\
\hline Middle/high school & $\mathrm{I}, 392$ & $33 \mid(23.78)$ & $355(25.50)$ & $333(23.92)$ & $373(26.80)$ & \\
\hline College or above & 640 & $199(31.09)$ & $157(24.53)$ & $172(26.88)$ & $112(17.50)$ & \\
\hline Income, $¥ /$ month, (\%)* & & & & & & 0.0015 \\
\hline$\leq 3,000$ & 1,262 & $282(22.35)$ & $306(24.25)$ & $345(27.34)$ & $329(26.07)$ & \\
\hline $3,00 \mathrm{I}-5,000$ & 868 & $245(28.23)$ & $220(25.35)$ & $195(22.47)$ & $208(23.96)$ & \\
\hline$>5,001$ & 108 & $32(29.63)$ & $34(31.48)$ & $20(\mid 8.52)$ & $22(20.37)$ & \\
\hline Smoking, (\%) & & & & & & $<0.000$ I \\
\hline Never & 1,667 & $466(27.95)$ & $447(26.8 I)$ & $402(24.12)$ & $352(21.12)$ & \\
\hline Current smoker & 470 & $81(17.23)$ & $100(21.28)$ & $130(27.66)$ & $159(33.83)$ & \\
\hline Former smoker & 101 & $12(11.88)$ & $13(12.87)$ & $28(27.72)$ & $48(47.52)$ & \\
\hline Physical activity, (\%) & & & & & & 0.2083 \\
\hline Inactive & 670 & $152(22.69)$ & $173(25.82)$ & $175(26.12)$ & $170(25.37)$ & \\
\hline Moderately active & 155 & $44(28.39)$ & $40(25.8 I)$ & $4 \mathrm{I}(26.45)$ & $30(19.35)$ & \\
\hline Very active & $|, 4| 3$ & $363(25.69)$ & $347(24.56)$ & $344(24.35)$ & $359(25.4 \mathrm{I})$ & \\
\hline BMI $\left(\mathrm{kg} / \mathrm{m}^{2}\right)$ & $25.12 \pm 3.43$ & $22.94 \pm 2.90$ & $24.78 \pm 2.91$ & $25.8 I \pm 2.79$ & $26.97 \pm 3.71$ & $<0.000$ I \\
\hline Underweight & 28 & $19(67.86)$ & $5(17.86)$ & $3(10.7 I)$ & I (3.57) & $<0.000$ I \\
\hline Normal weight & 1,095 & $424(38.72)$ & $302(27.58)$ & $225(20.55)$ & $144(13.15)$ & $<0.000$ I \\
\hline Overweight or obese & I,079 & $109(10.10)$ & $243(22.52)$ & $322(29.84)$ & $405(37.53)$ & $<0.000$ I \\
\hline Abdomen circumference $(\mathrm{cm})$ & $86.94 \pm 9.93$ & $79.48 \pm 8.56$ & $85.34 \pm 7.63$ & $89.23 \pm 8.25$ & $93.68 \pm 9.17$ & $<0.000$ I \\
\hline Hip circumference $(\mathrm{cm})$ & $98.6 I \pm 7.28$ & $95.12 \pm 6.84$ & $98.35 \pm 6.58$ & $99.8 \mathrm{I} \pm 6.97$ & $101.17 \pm 7.29$ & $<0.000$ I \\
\hline $\mathrm{SBP}(\mathrm{mmHg})$ & $133.00 \pm 20.18$ & $125.65 \pm 17.58$ & $132.5 \mid \pm 19.59$ & $|33.93 \pm 20.0|$ & $139.90 \pm 20.86$ & $<0.000$ I \\
\hline $\mathrm{DBP}(\mathrm{mmHg})$ & $83.72 \pm 13.03$ & $79.70 \pm 12.18$ & $83.21 \pm 12.32$ & $84.77 \pm 13.03$ & $87.21 \pm 13.42$ & $<0.000$ I \\
\hline Fasting blood glucose (mg/dL) & $5.57 \pm 1.42$ & $5.28 \pm 1.13$ & $5.47 \pm 1.48$ & $5.67 \pm 1.42$ & $5.87 \pm 1.55$ & $<0.000$ I \\
\hline Triglycerides (mmol/L) & $1.74 \pm 1.42$ & $1.38 \pm 1.01$ & $1.75 \pm 1.57$ & $1.8 \mathrm{I} \pm \mathrm{I} .18$ & $2.02 \pm 1.71$ & $<0.000$ I \\
\hline Total cholesterol (mmol/L) & $4.92 \pm 0.94$ & $4.8 \mathrm{I} \pm 0.86$ & $4.90 \pm 0.96$ & $4.94 \pm 0.90$ & $5.05 \pm 1.03$ & 0.0002 \\
\hline $\mathrm{HDL}(\mathrm{mmol} / \mathrm{L})$ & $1.22 \pm 0.28$ & $1.34 \pm 0.29$ & $1.22 \pm 0.28$ & $1.19 \pm 0.27$ & $1.15 \pm 0.24$ & $<0.000$ I \\
\hline $\mathrm{LDL}(\mathrm{mmol} / \mathrm{L})$ & $2.69 \pm 0.6 \mathrm{I}$ & $2.57 \pm 0.59$ & $2.67 \pm 0.63$ & $2.73 \pm 0.60$ & $2.8 I \pm 0.60$ & $<0.000$ I \\
\hline $\mathrm{ALT}(\mathrm{U} / \mathrm{L})$ & $22.61 \pm 17.13$ & $20.19 \pm 18.89$ & $21.49 \pm 13.36$ & $24.10 \pm 15.60$ & $24.65 \pm 19.58$ & $<0.000$ I \\
\hline AST (U/L) & $24.14 \pm 10.96$ & $23.86 \pm 14.13$ & $24.14 \pm 9.77$ & $24.10 \pm 8.35$ & $24.36 \pm 10.83$ & 0.9385 \\
\hline $\mathrm{Cr}(\mu \mathrm{mol} / \mathrm{L})$ & $76.67 \pm 15.17$ & $72.98 \pm 11.88$ & $75.52 \pm 16.45$ & $77.25 \pm 15.11$ & $80.93 \pm 15.74$ & $<0.000$ I \\
\hline Diabetes (\%) & 272 & $27(9.93)$ & $5 \mathrm{I}(18.75)$ & $82(30.15)$ & $122(41.18)$ & $<0.000$ I \\
\hline Hypertension (\%) & 1,045 & $170(16.27)$ & $236(22.58)$ & $276(26.4 I)$ & $363(34.74)$ & $<0.000$ I \\
\hline Hyperlipidemia (\%) & 1,142 & $184(16.11)$ & $277(24.26)$ & $325(28.46)$ & $356(31.17)$ & $<0.000$ I \\
\hline
\end{tabular}

Notes: Values are mean \pm SD, $\mathrm{n}(\%)$. The cut-off points of the quartiles are $93.87,127.46$, and $172.72 \mathrm{~cm}^{3}$. $* 29$ people did not register their income level information. Abbreviations: EAT, epicardial adipose tissue; HDL, high-density lipoprotein; LDL, low-density lipoprotein.

compared to those with lower prevalence of NAFLD. BMI is associated with both EAT and NAFLD, subjects with higher volume of EAT and NAFLD tended to have a higher BMI. The higher volume of EAT groups had a higher rate of being overweight or obese, and higher rate of NAFLD. Table 3 showed that the OR $(95 \% \mathrm{CI})$ of EAT affected CIMT and CAC score, in model 4 (adjusted for BMI on the basis of model 3: for CIMT $>0.8 \mathrm{~mm}, 1.001,[0.993$, 1.009], $P=0.8114$; for CAC score $>0,1.26$, [1.225, 1.295], $P<0.001$ ), thus distribution of fat (such as EAT) may be more appropriate than BMI.

Furthermore, percentage of DM, hypertension, and hyperlipidemia increased with increasing EAT volume. It is also confirmed that participants with NAFLD have a 
Table 2 Cardiovascular risk factors of the entire cohort stratified by quartiles of epicardial adipose tissue

\begin{tabular}{|c|c|c|c|c|c|c|}
\hline & $\begin{array}{l}\text { Overall } \\
(n=2,238)\end{array}$ & $\begin{array}{l}\text { Ist quartile } \\
(n=559)\end{array}$ & $\begin{array}{l}\text { 2nd quartile } \\
(n=560)\end{array}$ & $\begin{array}{l}\text { 3rd quartile } \\
(n=560)\end{array}$ & $\begin{array}{l}\text { 4th quartile } \\
(n=559)\end{array}$ & $P$-value \\
\hline CVH metrics (\%) & & & & & & $<0.000$ I \\
\hline 0 & I $3(0.58)$ & $0(0.00)$ & I (7.69) & $2(15.38)$ & 10 (76.92) & \\
\hline I & $100(4.47)$ & $8(8.00)$ & $15(15.00)$ & $29(29.00)$ & $48(48.00)$ & \\
\hline 2 & $319(14.25)$ & $36(11.29)$ & 66 (20.69) & 9I (28.53) & $126(39.50)$ & \\
\hline 3 & $519(23.19)$ & 72 (13.87) & $126(24.28)$ & I 48 (28.52) & $173(33.33)$ & \\
\hline 4 & $609(27.2 \mathrm{I})$ & $152(24.96)$ & I6I (26.44) & $169(27.75)$ & I $27(20.85)$ & \\
\hline$\geq 5$ & $678(30.29)$ & 291 (42.92) & $191(28.17)$ & I2I (I7.85) & $75(11.06)$ & \\
\hline CIMT (\%) & & & & & & $<0.000$ I \\
\hline$<0.8 \mathrm{~mm}$ & $\mathrm{I}, \mathrm{I} 27(50.36)$ & $373(33.10)$ & $28 I(24.93)$ & $273(24.22)$ & $200(17.75)$ & \\
\hline$\geq 0.8 \mathrm{~mm}$ & I, I I I (49.64) & $186(16.74)$ & $279(25.11)$ & $287(25.83)$ & $359(32.3 I)$ & \\
\hline CAC score (\%) & & & & & & $<0.000 \mathrm{I}$ \\
\hline$=0$ & I,886 (84.27) & $555(29.43)$ & $533(28.26)$ & $503(26.67)$ & $295(15.64)$ & \\
\hline$>0$ & $352(15.73)$ & $4(1.14)$ & $27(7.67)$ & $57(16.19)$ & $264(75.00)$ & \\
\hline NAFLD (\%) & $\mathrm{I}, 22 \mathrm{I}(54.56)$ & I58 (28.26) & $290(51.79)$ & $359(64.11)$ & $4 \mid 4(74.06)$ & $<0.000$ I \\
\hline
\end{tabular}

Abbreviations: $\mathrm{CVH}$, cardiovascular health; CAC, coronary artery calcium; CIMT, carotid intima-media thickness; NAFLD, non-alcoholic fatty liver disease.

higher risk of the aggravation of EAT volume. To the best of our knowledge, this study is the first to show the relation between NAFLD and the volume of EAT in a community population. We thus hypothesized that NAFLD contributes to the pathogenesis of CVD via the aggravation of EAT. We addressed the potential connection between the volume of EAT and NAFLD in a community population.

Our findings are consistent with previous studies. In the Heinz Nixdorf Recall Study, with 4,093 participants, Mahabadi et al found a significant association of cardiovascular risk factors with EAT volume in univariable and multivariable analyses. ${ }^{7}$ In a study involving 100 gender-controlled patients who were 50 years old with biopsy-proven NAFLD, patients with NAFLD tended to have increased arterial stiffness and EAT thickness. ${ }^{14}$ The interaction between heart function and liver fat has been proven by studies reporting an association between epicardial fat thickness and NAFLD. ${ }^{15,16}$ Perseghin et al reported that men with newly diagnosed fatty liver despite normal left ventricular (LV) morphological features and systolic and diastolic functions had increased epicardial fat and abnormal LV energy metabolism. ${ }^{17}$ In East Asia, a study with 1,473 participants discovered a significant association between increased EAT thickness and coronary artery calcification in Korean adults. ${ }^{18}$

The inflammatory state of NAFLD might affect the homeostasis of various organs as demonstrated for systemic atherosclerosis. Some clinical studies showed that ectopic fat depots have an important role in the pathogenesis of NAFLD. ${ }^{19,20} \mathrm{EAT}$ accumulation is part of the metabolic disorders re-elevated with the occurrence of fatty liver. High EAT may epitomize the severity of metabolic disorders, as emphasized by its association with liver fibrosis and nonalcoholic steatohepatitis, and may also be involved in the development of target organ damage, especially blood vessels, the heart, and the liver. ${ }^{21}$

Some experimental studies have shown the possible inflammatory mediators. An animal study pointed out that the rate of fatty acid liberated by EAT is about twice that of the perirenal depots and pericardial. ${ }^{32}$ In humans, a protein

Table 3 The OR $(95 \% \mathrm{Cl})$ of EAT affected CIMT and CAC score

\begin{tabular}{|c|c|c|c|c|}
\hline & \multicolumn{2}{|l|}{$\mathrm{CIMT}>0.8 \mathrm{~mm}$} & \multicolumn{2}{|l|}{ CAC score $>0$} \\
\hline & OR $(95 \% \mathrm{Cl})$ & $P$-value & OR (95\% CI) & $P$-value \\
\hline Model I & $1.033(1.023,1.044)$ & $<0.0001$ & $1.230(1.204,1.258)$ & $<0.001$ \\
\hline \multicolumn{5}{|l|}{ EAT volume (per $10 \mathrm{~cm}^{3}$ ) } \\
\hline Model 2 & $1.006(0.998,1.015)$ & 0.1371 & $1.213(1.186,1.242)$ & $<0.001$ \\
\hline \multicolumn{5}{|l|}{ EAT volume (per $10 \mathrm{~cm}^{3}$ ) } \\
\hline Model 3 & $1.004(0.996,1.013)$ & 0.3083 & $1.214(1.186,1.243)$ & $<0.001$ \\
\hline \multicolumn{5}{|l|}{ EAT volume (per $10 \mathrm{~cm}^{3}$ ) } \\
\hline Model 4 & $1.001(0.993,1.009)$ & 0.8114 & $1.26(1.225,1.295)$ & $<0.001$ \\
\hline EAT volume (per $10 \mathrm{~cm}^{3}$ ) & & & & \\
\hline
\end{tabular}

Notes: Model I without any adjustments; model 2 adjusted for age and gender; model 3 adjusted for model 2+ smoking status, hypertension, and diabetes mellitus; model 4 adjusted for model 3+ BMI.

Abbreviations: EAT, epicardial adipose tissue; CIMT, carotid intima-media thickness; CAC, coronary artery calcium. 
Table 4 Multivariate logistic regression analysis of risk for higher EAT volume elevation between groups with or without nonalcoholic fatty liver disease

\begin{tabular}{lllll}
\hline & OR & \multicolumn{2}{l}{$\mathbf{9 5 \%} \mathbf{C l}$} & P-value \\
\cline { 3 - 4 } & & $\begin{array}{l}\text { Lower } \\
\text { bound }\end{array}$ & $\begin{array}{l}\text { Upper } \\
\text { bound }\end{array}$ & \\
\hline Model I & 3.346 & $2.81 \mathrm{I}$ & 3.983 & $P<0.000$ I \\
Model 2 & 3.073 & 2.547 & 3.708 & $P<0.000$ I \\
Model 3 & 2.787 & 2.296 & 3.383 & $P<0.000$ I \\
Model 4 & 1.407 & I.II7 & I.773 & $P<0.005$ \\
\hline
\end{tabular}

Notes: Model I without any adjustments; model 2 adjusted for age and gender model 3 adjusted for model $2+$ smoking status, level of education and income, hypertension, and diabetes mellitus; model 4 adjusted for model $3+$ hip circumference, abdomen circumference, TG, LDL, HDL, ALT, BMI, and physical activity.

secreted by adipose tissue is associated with increased cardiovascular risk. ${ }^{22}$ Abnormal right ventricle geometry and increased LV mass are associated with increased volume of epicardial fat. ${ }^{23}$ In epicardial fat tissue of patients with CVD, a dense inflammatory infiltrate (mainly comprising macrophages) is commonly present. The EAT transcriptome includes B-cell-associated factors, T-cell and macrophage markers, TGF- $\beta 2$, and multiple chemokine ligands and chemokine receptors. ${ }^{1}$ The epicardial inflammatory molecules' secretion increases the arterial wall thickness, and is likely to promote atherogenesis. The atherogenic effects of epicardial fat tissue are caused by its intense proinflammatory activity, and also by its anatomical vicinity to the plaque. ${ }^{4}$

\section{Conclusion}

The strengths of this study are its sample size and its population-based design. However, its cross-sectional design limits the strength of the confidence of the correlation. CT is better than competing imaging modalities, which offers great spatial resolution of $0.4-0.6 \mathrm{~mm}$. The present study was unable to isolate NAFLD's direct effect on the development of CVD or cardiovascular events, thus further research is required. The relationship between the volume of EAT and inflammatory station of EAT, and the plasma biomarkers should be researched and we will focus on this in future.

In conclusion, our findings in a general community population provided evidence that the layer of EAT is strongly linked to NAFLD and cardiovascular risk factors. The findings may also imply the possibility of NAFLD contributing to the pathogenesis of CVD via the aggravation of EAT.

\section{Acknowledgment}

This work was supported by grants from the Medical and Health Science and Technology Innovation Project of Chinese Academy of Medical Sciences (no 201612M1009).

\section{Author contributions}

All authors contributed toward data analysis, drafting and revising the paper and agree to be accountable for all aspects of the work.

\section{Disclosure}

The authors report no conflicts of interest in this work.

\section{References}

1. Mazurek T, Zhang L, Zalewski A, et al. Human epicardial adipose tissue is a source of inflammatory mediators. Circulation. 2003;108(20) 2460-2466.

2. Chatterjee TK, Stoll LL, Denning GM, et al. Proinflammatory phenotype of perivascular adipocytes: influence of high-fat feeding. Circ Res. 2009;104(4):541-549.

3. Hirata Y, Tabata M, Kurobe H, et al. Coronary atherosclerosis is associated with macrophage polarization in epicardial adipose tissue. J Am Coll Cardiol. 2011;58(3):248-255.

4. Iacobellis G. Local and systemic effects of the multifaceted epicardial adipose tissue depot. Nat Rev Endocrinol. 2015;11(6):363-371.

5. Prati F, Arbustini E, Labellarte A, et al. Eccentric atherosclerotic plaques with positive remodelling have a pericardial distribution: a permissive role of epicardial fat? A three-dimensional intravascular ultrasound study of left anterior descending artery lesions. Eur Heart J. 2003;24(4):329-336.

6. Yerramasu A, Dey D, Venuraju S, et al. Increased volume of epicardial fat is an independent risk factor for accelerated progression of sub-clinical coronary atherosclerosis. Atherosclerosis. 2012;220(1):223-230.

7. Mahabadi AA, Berg MH, Lehmann N, et al. Association of epicardial fat with cardiovascular risk factors and incident myocardial infarction in the general population: the Heinz Nixdorf Recall Study. J Am Coll Cardiol. 2013;61(13):1388-1395.

8. Nakazato R, Dey D, Cheng VY, et al. Epicardial fat volume and concurrent presence of both myocardial ischemia and obstructive coronary artery disease. Atherosclerosis. 2012;221(2):422-426.

9. Petta S, Muratore C, Craxì A. Non-alcoholic fatty liver disease pathogenesis: the present and the future. Dig Liver Dis. 2009;41(9):615-625.

10. Wu R, Hou F, Wang X, et al. Nonalcoholic Fatty Liver Disease and Coronary Artery Calcification in a Northern Chinese Population: a Cross Sectional Study. Sci Rep. 2017;7(1):9933

11. Bhatia LS, Curzen NP, Byrne CD. Nonalcoholic fatty liver disease and vascular risk. Curr Opin Cardiol. 2012;27(4):420-428.

12. Lazo M, Hernaez R, Bonekamp S, et al. Non-alcoholic fatty liver disease and mortality among US adults: prospective cohort study. BMJ. 2011;343:d6891.

13. Söderberg C, Stål P, Askling J, et al. Decreased survival of subjects with elevated liver function tests during a 28-year follow-up. Hepatology. 2010;51(2):595-602.

14. Petta S, Argano C, Colomba D, et al. Epicardial fat, cardiac geometry and cardiac function in patients with non-alcoholic fatty liver disease: association with the severity of liver disease. J Hepatol. 2015;62(4) 928-933.

15. Iacobellis G, Barbarini G, Letizia C, Barbaro G. Epicardial fat thickness and nonalcoholic fatty liver disease in obese subjects. Obesity. 2014; 22(2):332-336.

16. Colak Y, Karabay CY, Tuncer I, et al. Relation of epicardial adipose tissue and carotid intima-media thickness in patients with nonalcoholic fatty liver disease. Eur J Gastroenterol Hepatol. 2012;24(6):613-618.

17. Perseghin G, Lattuada G, de Cobelli F, et al. Increased mediastinal fat and impaired left ventricular energy metabolism in young men with newly found fatty liver. Hepatology. 2008;47(1):51-58.

18. Kim BJ, Cheong ES, Kang JG, Kim BS, Kang JH. Relationship of epicardial fat thickness and nonalcoholic fatty liver disease to coronary artery calcification: From the CAESAR study. J Clin Lipidol. 2016; 10(3):e611-e626. 
19. van der Poorten D, Milner KL, Hui J, et al. Visceral fat: a key mediator of steatohepatitis in metabolic liver disease. Hepatology. 2008;48(2): 449-457.

20. Cheung O, Kapoor A, Puri P, et al. The impact of fat distribution on the severity of nonalcoholic fatty liver disease and metabolic syndrome. Hepatology. 2007;46(4):1091-1100.

21. Fracanzani AL, Pisano G, Consonni D, et al. Epicardial Adipose Tissue (EAT) Thickness Is Associated with Cardiovascular and Liver Damage in Nonalcoholic Fatty Liver Disease. PLoS One. 2016; 11(9):e0162473.

22. Pischon T, Girman CJ, Hotamisligil GS, Rifai N, Hu FB, Rimm EB. Plasma adiponectin levels and risk of myocardial infarction in men. JAMA. 2004;291(14):1730-1737.

23. Iacobellis $\mathrm{G}$. Relation of epicardial fat thickness to right ventricular cavity size in obese subjects. Am J Cardiol. 2009;104(11):1601-1602.

24. Song Q, Liu X, Wang A, et al. Associations between non-traditional lipid measures and risk for type 2 diabetes mellitus in a Chinese community population: a cross-sectional study. Lipids Health Dis. 2016;15:70.

25. Agatston AS, Janowitz WR, Hildner FJ, Zusmer NR, Viamonte M, Detrano R. Quantification of coronary artery calcium using ultrafast computed tomography. J Am Coll Cardiol. 1990;15(4):827-832.

26. Gorter PM, van Lindert AS, de Vos AM, et al. Quantification of epicardial and peri-coronary fat using cardiac computed tomography; reproducibility and relation with obesity and metabolic syndrome in patients suspected of coronary artery disease. Atherosclerosis. 2008;197(2):896-903.
27. Fan JG, Jia JD, Li YM, et al. Guidelines for the diagnosis and management of nonalcoholic fatty liver disease: update 2010: (published in Chinese on Chinese Journal of Hepatology 2010;18:163-166). J Dig Dis. 2011;12(1):38-44.

28. Farrell GC, Chitturi S, Lau GK, Sollano JD. Asia-Pacific Working Party on NAFLD. Guidelines for the assessment and management of non-alcoholic fatty liver disease in the Asia-Pacific region: executive summary. J Gastroenterol Hepatol. 2007;22(6):775-777.

29. Huang Y, Bi Y, Xu M, et al. Nonalcoholic fatty liver disease is associated with atherosclerosis in middle-aged and elderly Chinese. Arterioscler Thromb Vasc Biol. 2012;32(9):2321-2326.

30. Luijendijk P, Lu H, Heynneman FB, et al. Increased carotid intimamedia thickness predicts cardiovascular events in aortic coarctation. Int J Cardiol. 2014;176(3):776-781.

31. Lloyd-Jones DM, Hong Y, Labarthe D, et al. Defining and setting national goals for cardiovascular health promotion and disease reduction: the American Heart Association's strategic Impact Goal through 2020 and beyond. Circulation. 2010;121(4):586-613.

32. Marchington JM, Mattacks CA, Pond CM, Adipose tissue in the mammalian heart and pericardium: structure, foetal development and biochemical properties. Comp Biochem Physiol B. 1989;94(2):225-232.
Therapeutics and Clinical Risk Management

\section{Publish your work in this journal}

Therapeutics and Clinical Risk Management is an international, peerreviewed journal of clinical therapeutics and risk management, focusing on concise rapid reporting of clinical studies in all therapeutic areas, outcomes, safety, and programs for the effective, safe, and sustained use of medicines. This journal is indexed on PubMed Central, CAS,

\section{Dovepress}

EMBase, Scopus and the Elsevier Bibliographic databases. The manuscript management system is completely online and includes a very quick and fair peer-review system, which is all easy to use. Visit http://www.dovepress.com/testimonials.php to read real quotes from published authors. 